\title{
LINAJES PATERNOS DEL GRAN CHACO, UN ABORDAJE DESDE EL ADN
}

\author{
Gran Chaco paternal lineages, a DNA approach
}

\author{
Laura S. Jurado Medina ${ }^{1}$,Virginia Ramallo², Horacio Calandra ${ }^{3}$, \\ Guillermo Lamenza ${ }^{4}$, José Braunstein ${ }^{5}$, Susana Salceda ${ }^{6}$, Graciela Bailliet ${ }^{7}$
}

\begin{abstract}
Resumen
La región no recombinante del cromosoma $Y$ ha sido exitosamente utilizada para reconocer la estructura genética de los linajes paternos de poblaciones humanas. Este trabajo se integra al proyecto multidisciplinario "De las historias étnicas a la prehistoria en el Gran Chaco", involucra el estudio de individuos de diversa filiación étnica y se propone reconocer la estructuración en la fracción nativa de los linajes paternos. Tal información dará cuenta de la dinámica poblacional y de los patrones de distribución aportando así, elementos clarificadores de la compleja configuración de las poblaciones chaqueñas. En los 118 individuos analizados se identificaron 82 linajes, de los cuales $22 \%$ estuvieron presentes en más de un individuo dentro de una población o entre poblaciones, en ocasiones distantes geográficamente. El coeficiente de diferenciación entre poblaciones fue el mayor encontrado (FST $=21 \%$ ) en linajes autóctonos de poblaciones de Argentina ( $\mathrm{FST}=3 \%$ ). La red de haplotipos demuestra que los linajes presentan una subestructuración en 3 ramas principales, en cada una de las mismas participan linajes de distintos grupos, reflejando la ausencia de aislamiento entre los mismos y planteando interesantes interrogantes a la luz de los datos arqueológicos y etnolingüísticos.
\end{abstract}

\begin{abstract}
The non-recombinant $\mathrm{Y}$ chromosome region has been successfully used to recognize the genetic structure of human populations' paternal lineages. This paper is part of the multidisciplinary project "De las historias étnicas a la prehistoria en el Gran Chaco", and it involves the study of individuals from diverse ethnic affiliation. It is aimed at recognizing the native fraction structuring of paternal lineages accounting the population dynamics and distribution patterns, which provide clarifying elements of the complex configuration of the Chaco populations. 82 lineages were identified among the 118 individuals analyzed, $22 \%$ of them were present in more than one individual within a population or between populations, sometimes geographically distant. The coefficient of differentiation among populations found (21\%) is the highest in native lineages of Argentine populations (3\%). Haplotype network lineages show a substructuring of three main branches, composed by lineages from different groups, reflecting the absence of insulation between them and raising interesting questions in light of archaeological and ethnolinguistic data.
\end{abstract}

$<$ Biología Molecular $><$ Linajes Paternos $><$ Gran Chaco $>$

$<$ Molecular Biology $><$ Parental Lineages $><$ Gran Chaco $>$

Recibido: 03/04/2014 // Aceptado: 15/07/2014

Licenciada en Biología, IMBICE, SICPBA, CCT-CONICET - La Plata, laurisjurado@gmail.com

Doctora en Ciencias Naturales, Investigadora Asistente CONICET, vramallo@yahoo.com

3 Licenciado en Antropología, Investigador Independiente CONICET, hcalandra_@hotmail.com

4 Doctor en Ciencias, Becario Post Doctoral CONICET, FCNyM-UNLP, glamenza@fcnym.unlp.edu.ar

Doctor en Filosofía y Letras, Investigador Principal CONICET, jabraunstein@gmail.com

Doctora en Ciencias Naturales, Investigadora Principal CONICET, ssalceda@fcnym.unlp.edu.ar

Doctora en Ciencias Naturales - IMBICE-CONICET. 


\section{A manera de introducción}

En general, las investigaciones antropológicas atinentes al Chaco se han planteado a partir de distintas estrategias metodológicas procedentes de campos biológicos y culturales, constituyéndose así en una contribución de disciplinas específicas consideradas como ciencias sociales y/o antropología en sentido amplio. Es nuestro propósito en este trabajo aportar el quehacer integrado de algunas de esas disciplinas coactuando en un proceso de investigación multidisciplinar que apunta a dilucidar una problemática particular. Por tanto comprender la diversidad de los grupos humanos requiere abordar equilibradamente la indescifrable interrelación biosocial de los actores, acordando marcos y herramientas teórico-metodológicas para aprehender esa realidad.

Así, el presente trabajo constituye un avance en la reconstrucción del complejo proceso biocultural ocurrido en el Gran Chaco, uno de los ámbitos de poblamiento reciente de las Tierras Bajas sudamericanas y colonizado más tardíamente, que mantiene diversidad bioetnolingüística, estructurada a través de contactos interétnicos. Este extenso ámbito se comporta hoy como un verdadero laboratorio territorial especial para este abordaje multidisciplinar integrado. Desde esta perspectiva nuestro trabajo propone reconocer la estructuración en la fracción nativa de los linajes paternos interpretándola desde la etnografía, la lingüística y la bioarqueología, dando cuenta así de la dinámica poblacional y de patrones de distribución que resulten clarificadores para descifrar la compleja configuración de las poblaciones chaqueñas, sólo posible a partir de identificar el hilo conductor tal como se alude en el Mito de Ariadna.

\section{La enmarañada historia}

En un trabajo sobre sociología de los chaqueños, llegamos a la conclusión que era necesario diseñar una Carta Étnica que fuera modelo eficiente de la realidad y no una mera proyección de las cambiantes y variadas clasificaciones lingüísticas de la etnicidad. Para ello, sin lugar a dudas, se debía comenzar por delimitar cada una de las unidades sociopolíticas, consistentes en grupos de bandas, aliadas políticamente, que habitaban la región cuando se produjo la sedentarización de estos pueblos ocurrida, en la mayoría de los casos, a fines del siglo XIX (Braunstein, 2008). Esto implicaba la determinación de unidades sociales demográficamente más restringidas y culturalmente más homogéneas que las entidades virtuales que surgían del compromiso entre las defectuosas clasificaciones lingüísticas y las categorías étnicas regionales. Habíamos llegado a la convicción de que ese modo de organización en bandas era más o menos general, como una especie de "máximo común denominador" que hacía de interfase entre las formas particulares de las sociedades indígenas, y por lo tanto permitía el funcionamiento dinámico de ese espacio pleno de pueblos diferentes que en determinados momentos podían combinarse y recombinarse de acuerdo a las necesidades contingentes de la historia.

Este orden de segmentación del continuo social que identifica en la región la máxima extensión de la solidaridad así como la conciencia de una historia común en 
cada grupo indígena, permite penetrar en el oscuro edificio del conocimiento étnico del Gran Chaco. También esta forma organizativa y su dinámica es compatible con lo que los genetistas de población caracterizaron como modelo de "fisión-fusión". Neel y Salzano (1967) explican el patrón de la distribución de los elementos sociales y biológicos que caracterizan a las poblaciones del área. Como en la física de los fluidos, cada elemento distinto en el Gran Chaco, que sería la solución, semeja un soluto que ofrece gradientes a partir de un punto de máxima concentración. Una muestra no intencional de este patrón puede verse en el mapa de caracteres morfológicos que elaboró J. Boucherie para el Censo Indígena Nacional realizado en la década del sesenta en Argentina, donde, sin compadecerse de las categorías étnicas tradicionales, los valores de las diferentes variables consideradas se modifican gradualmente en el espacio (variación clinal) a partir de puntos definidos ${ }^{9}$ (Boucherie, 1968).

Con respecto a las lenguas que se hablan en la región, muchos datos indican que en el Chaco se han producido diversos y complejos fenómenos de contacto, interferencia y mezcla lingüística. Esto es altamente coherente con lo que acabamos de enunciar sobre la organización social y también con la etnohistoria de los chaqueños. En efecto, los fenómenos de comunicación en los pueblos tradicionales del Gran Chaco sin duda dependen del modelo social referido que se caracteriza por unidades progresivamente inclusivas entre las que alianzas más o menos estables de bandas -que se desplazaban tradicionalmente en un territorio determinado- eran las agrupaciones políticas más extensas. Además al concentrar en su interior el mayor número de intercambios de todo tipo, delimitaban las áreas de solidaridad y conciencia histórica común.

Contemplando este modelo en un plano sincrónico pueden detectarse dos grados diferentes en la intensidad de la comunicación. Por un lado estas alianzas de bandas, que denominamos regularmente "tribus", de una entidad demográfica restringida al orden de un par de miles de individuos, concentraban la mayoría de los circuitos de intercambio matrimonial, de bienes y lingüísticos. Por el otro, existía comunicación de una intensidad cuantitativamente menor y cualitativamente diferente entre tribus vecinas, ya fueran alianzas circunstanciales con afines extra-tribales, ya recíprocos robos de bienes o raptos de niños y mujeres.

8 Puede sintetizarse de manera esquemática: las agrupaciones intercambian información genética (y social, patrimonial y lingüística) de manera más o menos estable por períodos a veces muy prolongados, aunque ante condiciones extremas, negativas o positivas, es decir de disminución o aumento de la población, se fisionan o fusionan con otras, tendiendo a mantener cierta estabilidad demográfica. De esta manera, los intercambios continuos deben haber conducido forzosamente a la homologación de los códigos involucrados, aunque fueran éstos inicialmente muy diversos por la fusión de grupos heterogéneos. A la inversa, los procesos de fisión provocados por el aumento de la población y la formación de nuevas asociaciones entre grupos que comparten un porcentaje importante de los elementos de intercambio, deben conducir de manera normal a la deriva genética y cultural (lingüística).

9 Aunque los caracteres somáticos no sean hoy muy utilizados para clasificar poblaciones, ante el progresivo refinamiento del conocimiento genético, esta síntesis proyectada en el espacio parece particularmente ilustrativa del patrón característico de los rasgos y elementos propios de las diferentes poblaciones en el Gran Chaco. 
La situación se complica más si se piensa en diacronía, ya que la estabilidad de estas unidades dependía de situaciones muchas veces coyunturales, como el prestigio de jefaturas carismáticas o la accesibilidad de los recursos, produciéndose con variable frecuencia la descomposición de las bandas concurrentes y la recomposición tribal con aliados que podían ser muy distantes lingüística y culturalmente. Más aún si ahondamos en el tiempo arqueológico donde la estrategia metodológica marcada por la etnografía requirió de un abordaje territorial extensivo, más que intensivo y localizado, y de una sectorización también preliminar que incluyera los distintos ecotonos existentes, hábitats de antiguos pobladores, en los que la información disponible alude a un poblamiento continuo, aunque cronológicamente acotado, en ámbitos precisos, producto de un comportamiento nómade-restringido (Calandra y Salceda, 2004; Salceda y Calandra, 2003; Lamenza, 2013).

En este marco la información aportada por la genética adquiere especial significación por ser el resultado del análisis del cromosoma Y (sólo presente en el hombre) cuyas propiedades particulares y distintivas le otorgan la cualidad de indicador biológico de primer orden. Durante la meiosis, el cromosoma Y humano sólo recombina con el cromosoma $\mathrm{X}$ a través de 2 regiones pequeñas y por ello en gran parte se transmite por línea paterna a los hijos varones, en bloque, sin recombinarse. Consecuentemente, todas las variantes que se encuentran en las regiones específicas del cromosoma $\mathrm{Y}$, se originan por mutación.

Existen dos tipos de eventos mutacionales. En primer lugar, cambios de una base, con una tasa lo suficientemente baja como para ocurrir una vez en la historia del hombre, a través de los cuales se construyen haplogrupos o grupos de marcadores asociados con origen monofilético. Los haplogrupos se ordenan en una filogenia confiable que tiene una clara distribución geográfica (Underhill et al., 2001, Karafet et al., 2008), a partir de la cual es posible identificar linajes propios para América (Demarchi, 2009; Bailliet et al., 2011; Palatnik, 1989).

El segundo evento corresponde a los microsatélites, secuencias de 2 a 10 pares de bases que se repiten en tandem, que tienen una tasa mutacional cinco órdenes de magnitud mayor que los cambios de una base. Los microsatélites permiten la construcción de haplotipos, con los que se logran diferenciar a los individuos.

Cuando se combina la información aportada por los haplogrupos con la de los haplotipos, se logra analizar linajes filogenéticamente relacionados y, por métodos de máxima parsimonia, identificar linajes ancestrales, aproximándonos a la idea de tiempo involucrado en la diferenciación de los linajes (Jobling y Smith, 2003).

En general, los linajes paternos chaqueños presentan una alta proporción del haplogrupo autóctono para América y en todos los individuos pertenecientes a este haplogrupo se analizaron los haplotipos construidos a partir de 17 microsatélites (Ramallo et al., 2007; Ramallo et al., 2009). 


\section{Materiales y Métodos}

Se analizaron 118 individuos pertenecientes a las etnias: Ayoreo, Lengua, Chorote, Toba, Wichi y Mocoví, e individuos sin clara asignación étnica, residentes en las ciudades de Tartagal y Salta (Tabla 1). En todos los casos, las muestras biológicas fueron extraídas de donantes voluntarios, previa expresión de conformidad, a través de un protocolo de Consentimiento Informado, y codificadas de manera de mantener el anonimato de los donantes. La Base de Datos está disponible en el Instituto Multidisciplinar de Biología Celular (IMBICE- CIC, Pcia. de Buenos Aires).

Tabla 1. Localización geográfica y número de muestras analizadas

\begin{tabular}{|c|c|c|c|c|c|c|c|c|c|c|}
\hline Localidad & 胥 & 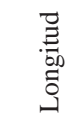 & $\stackrel{\mathscr{0}}{0}$ & $\sum_{3}^{3}$ & $\frac{\tilde{0}}{0}$ & $\begin{array}{l}0 \\
0 \\
0 \\
0\end{array}$ & $\begin{array}{l}5 \\
0 \\
0 \\
0 \\
\Sigma\end{array}$ & 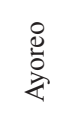 & 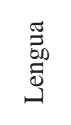 & \\
\hline Filadelfia, Paraguay & 22.23 & 60.02 & & & & & & 8 & 11 & \\
\hline $\begin{array}{l}\text { Santa Victoria Este, } \\
\text { Salta, Argentina }\end{array}$ & 22.16 & 62.42 & & 19 & 4 & 4 & & & & \\
\hline $\begin{array}{l}\text { Vaca Perdida, } \\
\text { Formosa, Argentina }\end{array}$ & 23.56 & 61.52 & & & 5 & & & & & \\
\hline $\begin{array}{l}\text { El Quimil, Formosa, } \\
\text { Argentina }\end{array}$ & & & & 5 & & & & & & \\
\hline $\begin{array}{l}\text { Pozo Yacaré, } \\
\text { Formosa, Argentina }\end{array}$ & & & & 8 & & & & & & \\
\hline $\begin{array}{l}\text { Laguna Yema, } \\
\text { Formosa, Argentina }\end{array}$ & 24.14 & 61.15 & & 12 & & & & & & \\
\hline $\begin{array}{l}\text { El Quebracho, } \\
\text { Formosa, Argentina }\end{array}$ & 23.34 & 61.87 & & 6 & & & & & & \\
\hline $\begin{array}{l}\text { San Lorenzo, } \\
\text { Charata, Chaco, } \\
\text { Argentina }\end{array}$ & 27.17 & 61.11 & & & & & 10 & & & \\
\hline $\begin{array}{l}\text { Tartagal, Salta, } \\
\text { Argentina }\end{array}$ & 22.31 & 63.47 & 14 & & & & & & & \\
\hline Salta, Argentina & 24.48 & 65.25 & 12 & & & & & & & \\
\hline Total & & & 26 & 50 & 9 & 4 & 10 & 8 & 11 & 118 \\
\hline$\%$ & & & 0.22 & 0.42 & 0.08 & 0.03 & 0.08 & 0.07 & 0.09 & 1.000 \\
\hline
\end{tabular}

Los linajes Q1a3a fueron determinados en trabajos anteriores (Bianchi et al., 1998; Ramallo et al., 2010) y algunas muestras Ayoreo y Lengua fueron identificadas dentro del haplogrupo Q1a3* (Bailliet et al., 2009). Los haplotipos fueron construidos a través del análisis de 17 microsatélites (YFiler - Life Technology). 
La variabilidad inter e intrapoblacional fue examinada a través del programa Arlequin ver 3.0 (Excoffier y Schneider, 2005). Se utilizó AMOVA (subdivisión jerárquica de la varianza) para el análisis de los haplotipos (Weir y Cockerham, 1984).

Se empleó el programa Network (v 4.6.0.0 - www.fluxus-engineering.com) para reconstruir redes filogenéticas e inferir linajes ancestrales, utilizando el algoritmo "Median Joinings" (Bandelt et al., 1999). Dado que los microsatélites poseen tasas mutacionales diferenciales, se otorgó un peso relativo a la tasa mutacional de cada locus utilizando la fórmula de estimación de Muzzio et al., (2010).

\section{Resultados}

En los 118 individuos se distinguieron 82 haplotipos, 64 resultaron únicos y 18 de ellos se encontraron en 2 individuos o más. Los linajes compartidos ocurrieron tanto dentro de las etnias como entre etnias. El orden de los marcadores fue 456, 389I, 390, 389II, 458, 19, 385I, 385II, 393, 391, 439, 635, 392, GATA, 437, 438, 448.

De la aplicación del test de AMOVA surge que el porcentaje de variación dentro de las poblaciones es de $78,44 \%$ y entre poblaciones $21.26 \%$. Es de resaltar que el índice de fijación encontrado ( $F s t=0.21264$, Tabla 2 ) es uno de los valores más altos hallados hasta el momento.

Tabla 2. AMOVA. Distancia basada en la suma de las diferencias al cuadrado (RST). (Weir y Cockerham, 1984; Excoffier, Smouse y Quattro, 1992; Weir, 1996)

\begin{tabular}{|c|c|c|c|c|}
\hline Fuente variación & d.f & Suma de cuadrados & Varianza & Porcentaje variación \\
\hline Entre poblaciones & 28 & 43396.539 & $98.50238 \mathrm{Va}$ & 21.26 \\
\hline Dentro poblaciones & 330 & 120361.464 & $364.73171 \mathrm{Vb}$ & 78.74 \\
\hline Total & 358 & 163758.003 & 463.23408 & \\
\hline $\begin{array}{c}\text { Índice de Fijación FST } \\
0.21264\end{array}$ & & & & \\
\hline
\end{tabular}

Cincuenta y tres haplotipos, pertenecientes a 80 individuos, se ordenaron en una Red Mediana que evidencia un nodo central no hallado en el muestreo. Los círculos rojos representan linajes ausentes, pero necesarios para explicar, por el método de máxima parsimonia, la aparición del resto de los linajes. Desde el nodo central parten 3 ramas mayores a las que hemos denominado clado I, II y III, cada una de las cuales se inicia en un linaje único que divergió del ancestral, en el centro de la red, por una sola mutación en el caso de los nodos II y III, y por 2 mutaciones, para el nodo I. Desde este fundador se suceden los linajes que van adquiriendo mutaciones desarrollando linajes derivados. Las tres ramas poseen individuos de distintas etnias, denotando interrelación entre las mismas a nivel de linajes masculinos (Figura 1). 
Al utilizar el estadístico Rho para la datación de cada rama, se obtuvo $8400 \pm$ 989 años A.P. para el clado II y $18200 \pm 2213$ años A.P. para el clado I, resultado que sugiere claramente que la diversificación de los linajes comenzó mucho antes de que el Gran Chaco Meridional fuera poblado (Calandra y Salceda, 2004; Lamenza et al., 2011 a y b). Aún aquellos linajes que mostraron menor antigüedad no fundamentarían aún diferenciación regional, puesto que las dataciones radiocarbónicas disponibles hasta el momento sólo refieren al 300 DC para los sectores Central y Ribereño (Lamenza et al., 2011 a y b), y al 500 AC para la cultura San Francisco con influencia en el sector subandino chaqueño (Dougherty, 1974; Ortiz, 2003). En este grupo incluimos a una de las subramas del clado III con una antigüedad de $4900 \pm 989$ años A.P. (integrada por Lengua y Ayoreo de Paraguay) y la subrama del clado II, representada por aquellos linajes que adquirieron una variante 16.10 en el locus DYS385b (particularmente Wichi y Toba).

Figura 1. Red Mediana de haplotipos construidos a partir de 17 STR.

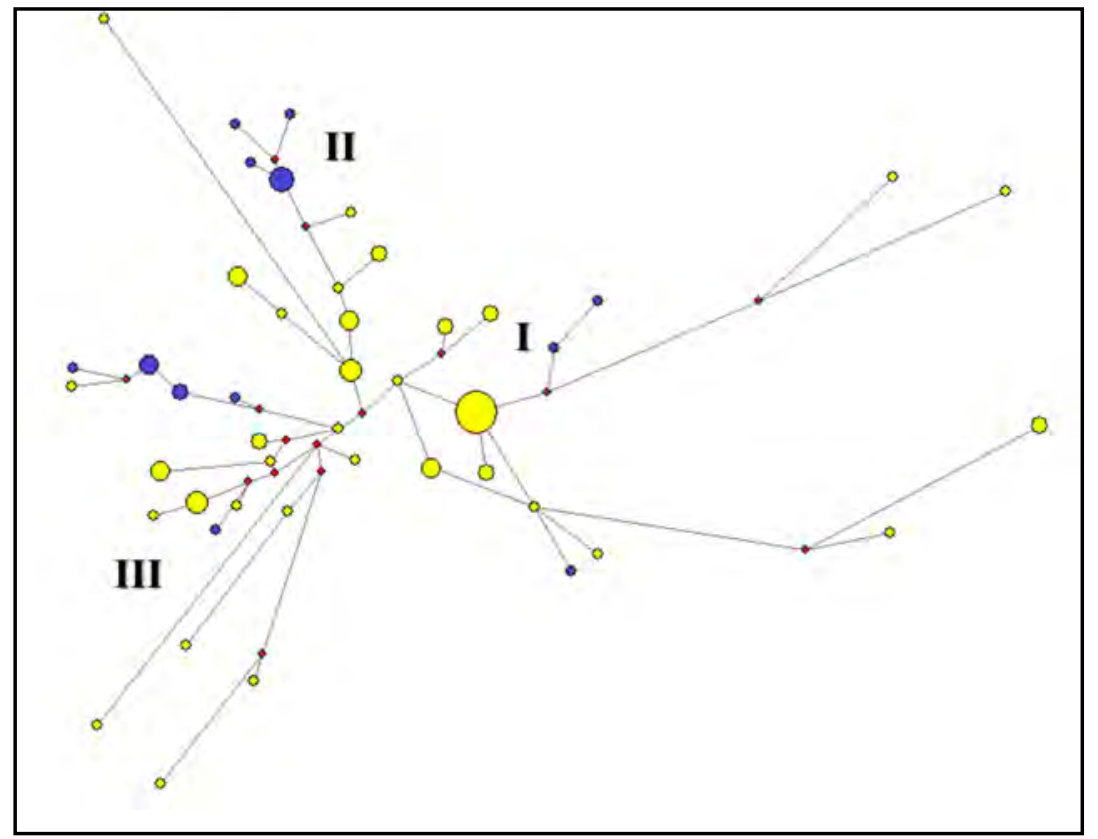

Fuente: Red Mediana de haplotipos construidos a través de 17 microsatélites construida a través del programa Network. La frecuencia de los haplotipos es proporcional al tamaño de los círculos. Los amarillos representan individuos del Chaco Argentino. Los círculos azules representan individuos Ayoreo y Lengua de Paraguay. Los círculos anaranjados son individuos Wichi con la variante 16.1 en el locus DYS385.

\section{Discusión e interpretación multidisciplinar}

Las poblaciones chaqueñas muestran una gran diversificación, sin evidencia de aislamiento reproductivo entre ellas, ya que linajes idénticos fueron compartidos entre distintas poblaciones. 
Homólogamente, como corolario del modelo social propuesto para los pueblos chaqueños, períodos de disturbios y tensiones debieron favorecer en el Gran Chaco una tendencia a producir homogeneización de pautas culturales, incluyendo la lengua. Mientras que tiempos de estabilidad deben haber conducido a diferenciación y deriva. Esto último explica el fenómeno de intensa variación dialectal que se observa en las lenguas mayoritarias, las que configuran "complejos lingüísticos" o inclusive verdaderas "cadenas dialectales".

Sin embargo, sería un error desconocer que estas tensiones contradictorias operan simultáneamente en las sociedades chaqueñas ya que la progresiva divergencia y "especialización" en el seno de las tribus tiene como contrapartida la eventual mezcla cultural en los confines de esas unidades. Esto conduce a la conclusión de que áreas periféricas de los conjuntos tribales que hablan variedades o dialectos lingüísticamente afines -conjuntos a los que hemos propuesto denominar "complejos étnicos" en lugar de las "etnias" que reconoce la clasificación tradicional- deben haber sido propensas a la formación de variedades culturales nuevas, incluyendo frecuentes fenómenos de generación de lenguas mixtas. Así, con respecto a la comunicación de los patrimonios culturales, consideramos dos clases de movimiento: uno centrípeto, de deriva cultural y lingüística en épocas de estabilidad y en el centro de los grandes complejos étnicos, y otro centrífugo de mezcla e interferencia en épocas de disrupción y en la periferia de las áreas de mayor homogeneidad. De la composición de estas fuerzas habría emergido la recurrente imagen de unidad regional junto a la sorprendente dinámica de diferenciación que presenta una especie de calidoscopio abigarrado de alrededor de medio centenar de unidades étnicas discretas que hablan una veintena de lenguas.

Los procesos de mestizaje, implicando hibridación y "mezcla" biológica y cultural en lapsos de tiempo relativamente breves de pocas generaciones, pueden explicar sin dificultad las modificaciones ocurridas a partir de fines del XVII por el flujo de los indígenas inicialmente encomendados y posteriormente amalgamados y desplazados inicialmente hacia el Chaco oriental, y posteriormente hacia el norte del Pilcomayo.

Los datos demográficos parecerían también ofrecer argumentos en esta dirección. Aunque B. Susnik afirma que la aparición tardía de los grupos enlhetenenlhet se originó en una migración desde el occidente, una visión global e histórica del Gran Chaco no ofrece una zona intersticial donde un pueblo como éste pudiera haber vivido durante los siglos XVII y XVIII. Por el contrario estos pueblos comienzan a ser consignados por las fuentes hacia el norte del Bermejo al mismo tiempo que otros desaparecen "misteriosamente" al sur de ese río. Se trata de las bandas acriolladas de los "calchaquíes" de Santa Fe, una amalgama de los evadidos de los pueblos de indios durante la sublevación general de 1630 y de los no encomendados que habían quedado en los montes subsistiendo de la recolección o de la cacería especializada, unificados mediante el gran recurso de la homologación de un sistema de reglas laxo que hacía posible la comunicación social (exogamia, uxorilocalismo, alianzas de bandas formadas por la expansión de familias extensas bilaterales), un pidgin de la normativa, una suerte 
de lengua franca sociológica, seguramente preexistente, pero que tal vez haya tomado su forma definitiva en los mismos pueblos de indios, antes de la prohibición de las mezclas étnicas ${ }^{10}$. Muchas de esas bandas debieron desplazarse hacia el norte a partir de los comienzos del XVIII en consonancia con el aumento de la presión española desde el Tucumán.

Figura 2. Carta Étnica del Gran Chaco

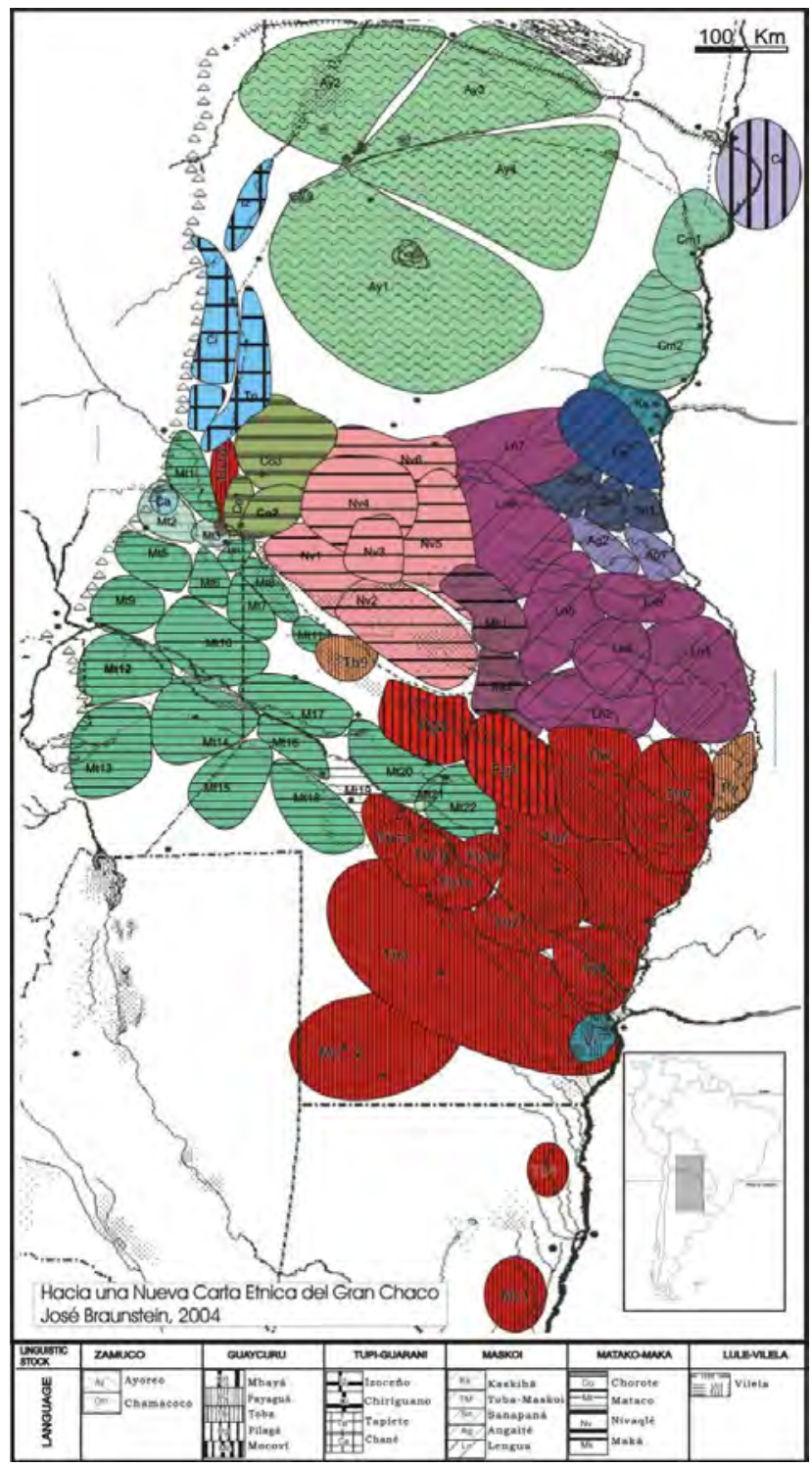

Fuente: Hacia una nueva carta étnica del Gran Chaco (Braunstein, 2004)

${ }^{10}$ La prohibición de incluir indígenas de diferentes proveniencias en los pueblos de indios de las encomiendas aparece tardíamente en las Leyes de Indias. 
La Figura 2 representa la conformación de la Carta Étnica del Gran Chaco. Las líneas cerradas refieren a los límites de cada una de las unidades sociopolíticas consistentes de grupos de bandas aliadas políticamente que vivían en la región cuando se produjo la sedentarización (CA fines del s. XIX). Las diferentes tonalidades pretenden representar la proporción aproximada de participación en los diferentes géneros de vida que pueden reconocerse para los chaqueños históricos. En particular el azul representa al género de vida de agricultores y alfareros; el verde identifica a las bandas de recolectores y mariscadores y el rojo a los cazadores especializados. El resto de las tonalidades constituirían en principio modos de vida "híbridos".

En otro orden de cosas, el análisis temporal de la diversificación de algunos linajes en las redes evidenciaría que la diferenciación a nivel molecular trasciende los límites de Sudamérica ya que los valores cronológicos absolutos señalan que la antigüedad del hombre sudamericano ronda los 12500 años A.P. (Dillehay, 2008) y todos ellos los límites del Chaco en cuanto, actualmente,los primeros registros de ocupación humana chaqueña datan del Holoceno Tardío ${ }^{11}$.

La cronología absoluta del Chaco prehispánico es indicativa de que las primeras poblaciones que materializaron una ocupación efectiva en la región lo hicieron cuando otros lugares de Sudamérica se encontraban preferentemente ocupados y con desarrollos culturales particulares. Estos grupos humanos, movilizados por distintas razones de sus lugares de origen y con una cultura material desarrollada fuera de los lindes chaqueños, llegan a la región para asentarse en este nuevo espacio, adquiriendo allí cánones culturales propios. El fingerprint molecular de estos pobladores está representado en la red mediana por los diferentes clados individualizados.

Así y tal como se expresa en la Figura 3, el ingreso de estos primeros pobladores se relaciona con grupos que disponían de conjuntos cerámicos representativos de modalidades presentes en otros sectores de las Tierras Bajas que, en fechas anteriores al inicio de la era cristiana, se ubicaban en ámbitos más septentrionales, desplazándose de norte a sur a través de dos vías, generando de este modo, dos rutas o canales de comunicación. La primera, subandina, integra la zona que ha sido denominada Área Pedemontana (Nuñez Regueiro y Tartusi, 1987; Rivera Casanovas, 2003). Las primeras ocupaciones del Chaco Meridional están registradas en el extremo oeste del sector central, en el sitio El Quebracho (1700+40 ${ }^{14} \mathrm{C}$ años $\mathrm{AP}$ ) que se presenta como el primer y único espacio formal de inhumación que involucra enterratorios primarios individuales y múltiples en tierra con bienes asociados de forma diferencial (Calandra et al., 2012). Este sitio se encuentra aún en etapa de

\footnotetext{
${ }^{11} \mathrm{Al}$ momento, las referencias de ocupación humana más tempranas son escasas y limitadas al ámbito marginal del Chaco como por ejemplo la región de Ñuapua (Arellano, 1986); Pantanal (Schmitz et al., 1998); Mato Grosso y Rondonia (Miller, 1987). Por ello, la escasez de indicadores fehacientes de ocupación humana en el interior del territorio obliga a reflexionar sobre posibles razones que, y tal como han sido planteadas para otras regiones de Sudamérica, incluyen datos insuficientes, baja visibilidad arqueológica propia de este tipo de ambiente, o a cuestiones referidas a la realidad imperante en esos tiempos, indicativa de muy baja densidad de población y/o dependencia de los grupos humanos a explotar determinadas zonas (Dillehay, 2008: 32).
} 
excavación, resaltando hasta el momento la ausencia de cerámica, así como la presencia de bienes trabajados en piedra (hachas pulidas) y concha (cuentas confeccionadas sobre Megalobulimus sp.), todos ellos aspectos merecedores de un análisis exhaustivo dada su excepcionalidad. Es de remarcar que casi la totalidad de los sitios arqueológicos chaqueños, especialmente aquellos de la periferia regional, tiene a la alfarería como indicador de primer orden (De Feo et al., 2003; Balbarrey et al., 2003; Calandra et. al., 2004; Ryden, 1948). Sus afinidades bioculturales resultan análogas a la subrama de clado III con clara representación en el sector subandino del Gran Chaco.

\section{Figura 3}

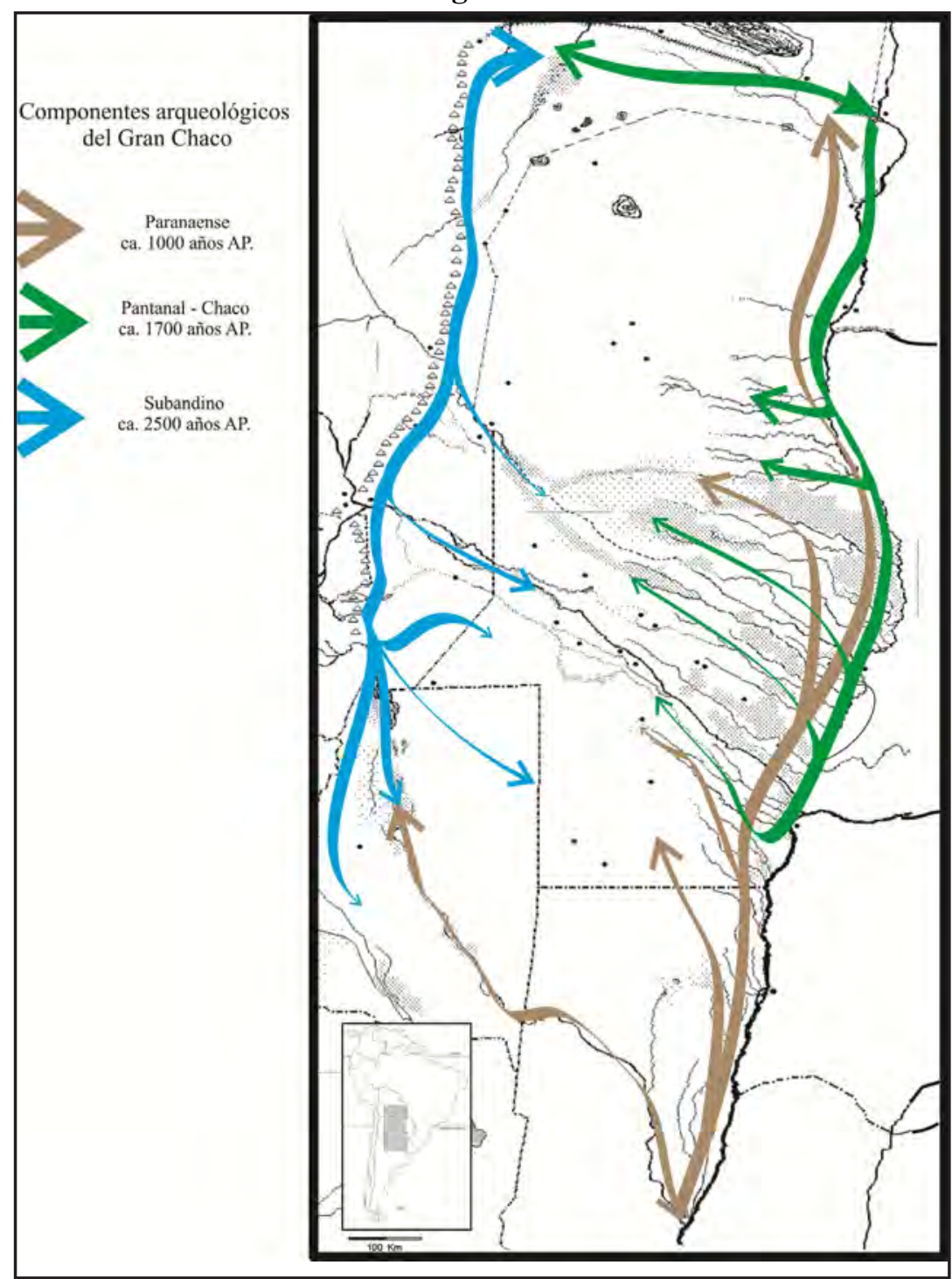

Fuente: Representación esquemática de los principales componentes arqueológicos del Gran Chaco 
El segundo canal de comunicación, oriental, vía Mato Grosso, se materializa en los sitios ribereños pertenecientes a la localidad arqueológica El Cachapé, con fechados radiocarbónicos desde el $1690 \pm 90$ a $820 \pm 70{ }^{14} \mathrm{C}$ años A.P.. Estas sociedades, principalmente pescadoras, cazadoras-recolectoras, establecen un canal sostenido que conforma un agrupamiento particular en el Sector Ribereño Paraguay-Paraná al que denominamos Componente Pantanal-Chaco (Lamenza, 2013). Sus portadores podrían particularizar aquellos linajes moleculares representados por la subrama del clado II en directa vinculación con el hipotético ancestro molecular.

A partir del $600 \mathrm{AD}$ identificamos arqueológicamente una intensa ocupación del espacio chaqueño, reconociéndose la diversidad cultural propia de desarrollos locales por parte de los distintos grupos humanos (Calandra y Salceda, 2004; Lamenza et al., 2011; Lamenza, 2013; Salceda y Calandra, 2003). Ya para comienzos del primer milenio de la Era, se documentan evidencias de nuevas ocupaciones humanas al sur de la confluencia Paraná Paraguay, con desplazamiento sur-norte y rasgos culturales propios del ámbito general del Río Paraná, conformando lo que denominamos Componente Paranaense chaqueño. Entrando en la Pequeña Edad de Hielo (ca.1200 AD) este componente comienza a reconocerse al norte de la confluencia Paraná-Paraguay. En un primer momento se presenta difusamente sobre el componente anterior y para momentos más tardíos se manifiesta plenamente con la incorporación de aquel perfil molecular que alude a la diversificación cronológicamente más antigua de los linajes moleculares.

Las características de los sitios arqueológicos adscriptos a este último componente indican algún tipo de interacción o sistema de comunicación vigente en relación con la denominada entidad arqueológica Goya-Malabrigo (Garizoain et al., 2013; Lamenza et al., 2013). Es importante destacar que las últimas investigaciones en el área de mayor expresión de esta entidad confirman su utilidad como unidad de análisis y, además, incorporan rasgos a considerar como la vida aldeana, construcciones monticulares, horticultura doméstica y desarrollo de jerarquías sociales (Bonomo, 2012; Bonomo et al., 2011; Politis y Bonomo, 2012).

En síntesis y en este marco, es sugerente la información que brinda la biología molecular, compatible con la evidencia arqueológica, confirmando un poblamiento del Gran Chaco por parte de poblaciones con diversidad biocultural marcada. Posteriormente y en términos generales, el desarrollo sostenido en la región los reúne culturalmente, aunque conservando rasgos que aluden a sus trayectorias particulares. Así, molecularmente, la variabilidad biológica permitiría reconocer características genéticas antiguas llegadas tardíamente al Chaco, en tanto que linajes relativamente recientes aparecen ocupando el territorio tempranamente.

La información aportada por la biología molecular muestra de este modo, ser análoga a las evidencias bioarqueológicas, lingüísticasy demográficas. 


\section{Referencias Bibliográficas}

Arellano, J. 1986. "Ñuapua, un asentamiento paleoindígena en Bolivia". En: Prehistoricas 1, Carrera de Antropología y Arqueología, UMSA, pp. 49-61.

Bailliet, G. V.; Ramallo, M.; Muzzio, A.; García, M.R.; Santos, E.L.; Alfaro, J. E.; Dipierri, S.; Salceda, F. R.; Carnese, C. M.; Bravi, N.O.; Bianchi y Demarchi, D. A. 2009. "Brief Communication: Restricted Geographic Distribution for Y-Q* Paragroup in South America". En: American Journal Physical Anthropolology, $\mathrm{N}^{\circ} 140$, pp. 578-582.

Bailliet, G.; Ramallo, V.; Muzzio, M.; Santos, M.R.; Motti. J.B.M.; Bianchi, N.O. y Bravi, C.M. 2011. "Antecedentes y nuevos aportes en el estudio del Cromosoma Y en poblaciones humanas Sudamericanas". J Basic and Applied Genet. (BAG). Vol. XXII (1).

Balbarrey, G.; Calandra H. A.; Couso, G.; Lamenza, G. y Aguirre, B. 2003. Nuevos aportes al análisis cerámico del sector central del Gran Chaco argentino. En: Actas del XXIII Encuentro de Geohistoria Regional, pp. 350-363.

Bandelt, H. J.; Forster, P. y Röhl, A. 1999. "Median-joining networks for inferring intraspecific phylogenies". En: Molecular Biology Evolution, $\mathrm{N}^{\circ}$ 16, pp. 37-48.

Bianchi, N. O.; Catanesi, C. L.; Bailliet, G.; Martinez-Marignac, V. L.; Bravi, C. M.; Vidal-Rioja, L. B.; Herrera, R. J.; López-Camelo, J. S. 1998. "Characterization of ancestral and derived Y-chromosome haplotypes of New World native population". Am. J. Hum. Genet. Vol. 63, pp. 1862-1871.

Bonomo, M. 2012. Historia prehispánica de Entre Ríos. Fundación de Historia Natural Félix de Azara. Buenos Aires.

Bonomo, M.; Politis, G. y Gianotti García, C. 2011. "Montículos, jerarquía social y horticultura en las sociedades indígenas del Delta del Río Paraná (Argentina)". En: Latin American Antiquity. Vol. 22 (3), pp. 297-333.

Boucherie, J. G. 1968. Los indios toba del Chaco argentino. Censo Indígena Nacional. Ministerio del Interior. Buenos Aires, Vol. 2, pp. 101-47.

Braunstein, J. 1989. Matako - Dialecto bananero. Contribución para el Intercontinental Dictionary Series Wordlist editado por Mary Ritchie Key (Universidad de California en Irvine).

VIII, pp. 3-90.

Hacia una nueva carta étnica del Gran Chaco. Las Lomitas. Vol.

2004. La dinámica de los pueblos indígenas en el curso medio e inferior del Bermejo desde fines del S. XIX. En: Actas del Vo Congreso Argentino de Americanistas. Tomo 2, Ed. Dunken, Buenos Aires, pp. 63-94.

2008. "Liderazgo, representatividad y control social en el Gran Chaco Sudamericano”. En: Braunstein José y Meichtry Norma (Eds.) Editorial Universitaria del Nordeste (Eudene), Corrientes, pp. 313.

Braunstein, J. A.; Salceda, S. A.; Calandra, H. A.; Méndez, M. G. y Ferrarini, S. O. 2002. "Historia de los chaqueños -Buscando en la 'papelera de reciclaje' de la antropología sudamericana". En: Acta Americana, Journal of the Swedish Americanist Society, Vol. 10 (1), pp. 59-88. 
Calandra, H. A.; Balbarrey, G.; Couso, G.; Lamenza, G.; Aguirre, B. y Duhalde, N. 2004. "El Sitio Las Bolivianas (Formosa): análisis comparativo del material cerámico del Sector Central del Gran Chaco argentino". En: Actas XXIV Encuentro de Geohistoria Regional Resistencia, Chaco, pp. 44-54.

Calandra, H. A.; Lamenza, G. y Salceda, S. 2012. "Arqueología Pública y Pueblos Originarios en el Chaco Central: Ancestría e Identidad". En: Estudios y Contribuciones: homenaje a la doctora Norma Cristina Meichtry. Maeder et al., (Coordinadores). Contexto Libros, Resistencia, pp. 45-70.

Calandra, H. A. y Salceda, S. A. 2004. "El territorio y sus ocupantes: ¿Qué, quienes cómo y cuándo?” En: Folia Histórica del Nordeste Resistencia, Chaco, $\mathrm{N}^{\circ} 15$, pp. 107-128.

De Feo, C.; Calandra, H. A.; Santini, M.; Aguirre, B., Lamenza, G.; Lanciotti, M.; Del Papa L. y Porterie, A. 2003. "Localización espacial y caracterización cultural de sitios arqueológicos del Gran Chaco Meridional”. En: XXII Encuentro de Geohistoria Regional. Chaco, Argentina, pp. 263-294.

Dillehay, T. 2008. Profiles in Holocene History. Helaine Silverman and William H. Isbell (Eds.) Handbook of South American archaeology. New York. Springer. pp. 29-43.

Demarchi, D. A. 2009. "Microsatélites, distancias genéticas y estructura de poblaciones nativas sudamericanas". En: Rev. Argent. Antropol. Biol. Vol. 11(1), pp. 73-88.

Dougherty, B. 1974. Nuevos aportes para el conocimiento del Complejo Arqueológico San Francisco (Sector septentrional de la Región de las Selvas Occidentales, subárea del Noroeste Argentino). Tesis Doctoral. Facultad de Ciencias Naturales y Museo. Universidad Nacional de La Plata.

Excoffier, L. y Schneider G. L. 2005. “Arlequin ver. 3.0: An integrated software package for population genetics data analysis". En: Evolutionary Bioinformatics Online 1.

Excoffier, Smouse y Quattro. 1992. "Analysis of molecular variance inferred from metric distances among DNA haplotypes: Application to human mitochondrial DNA RFLPdata". En: Genetics N 131, pp. 479-491.

Garizoain, G.; Lamenza, G. y Calandra, H. A. 2013. Arqueología Chaqueña 6: Alfarería con apéndices modelados en el Chaco Meridional. En: XVIII Congreso Nacional de Arqueología. Universidad Nacional de La Rioja. La Rioja, Argentina.

Jobling, M. A. y Tyler-Smith, C. 2003. "The human Y chromosome: An evolutionary marker comes of age". En: Nature Review Genetics. N 4, pp. 598-612.

Karafet, T. M.; Mendez, F. L.; Meilerman, M. B.; Underhill, P. A.; Zegura, S. L. y Hammer, M. F. 2008. "New binary polymorphisms reshape and increase resolution of the human Y chromosomal haplogroup tree". En: Genome Research. $N^{\circ} 18$, Vol. 5, pp. 830-8.

Lamenza, G. 2013. El hombre y el ambiente en el Holoceno Tardio del Chaco Meridional. Catamarca, Universidad Nacional de Catamarca.

Lamenza, G.; Calandra, H. y Salceda, S. 2011a. "Desarrollo cultural prehispánico: una mirada desde el Chaco". En: XXXI Encuentro de Geohistoria Regional. 
Concepción del Uruguay (Entre Ríos, Argentina). Instituto de Historia de la Facultad de Humanidades, Artes y Ciencias Sociales. UADER.

Lamenza, G.; Calandra, H. A. y Salceda S. 2011b. Avances en el conocimiento arqueológico del Sector Ribereño Paraná-Paraguay. El Hombre, el Medio y sus relaciones. Silvera de Buenader y Martínez de Montiel (Comps). Universidad Nacional de Catamarca, pp. 153-176.

Lamenza, G.; Santini, M.; Salceda, S. y Calandra, H. A.. 2013. El Chaco Meridional en perspectiva regional: esferas de interacción e identidad. En: $5^{\circ}$ Encuentro de Discusión Arqueológica del Nordeste, pp. 18.

Miller, Eurico Th. 1987. "Pesquisas arqueólogicas paleoindígenas no Brasil Occidental”. En: Estudios Atacameños. Vol. 8, pp. 37-61.

Muzzio, M.; Bravi, C. M.; Bailliet, G. 2010. “A method for assignment of the weight of characters". En: American. Journal Physical Anthropology V143 (3), pp. 488-92.

Neel, J. V. y Salzano, F. M. 1967. Further studies on the Xavante Indians. X. Some hypotheses-generalizations resulting from these studies. American Journal of Human Genetics. V 19, pp. 554-574.

Nuñez Regueiro, V. y Tartusi, M. 1987. “Aproximación al estudio del Área Pedemontana Sudamericana”. En: Cuadernos del Instituto Nacional de Antropología, Buenos Aires. Vol. 12, pp. 125-160.

Ortiz, G. 2003. "Estado actual del conocimiento del denominado Complejo o Tradición Cultural San Francisco, a 100 años de su descubrimiento". En: La Mitad Verde del Mundo Andino: Estado Actual de las Investigaciones Arqueológicas en la Vertiente Oriental de los Andes y Tierras Bajas de Bolivia y Argentina. Ortiz G. y B. Ventura (Eds.), Universidad Nacional de Jujuy, pp. 23-72.

Palatnik, M. 1989. “Antropogenética de los grupos sanguíneos en Latinoamérica”. En: Cuadernos del Instituto Nacional deAntropología y Pensamiento Latinoamericano. Vol. 35. Nro. 1.

Politis, G. y Bonomo, M. 2012. "La entidad arqueológica Goya-Malabrigo (Ríos Paraná y Uruguay) y su filiación Arawak”. En: Sociedade de Arqueología Brasileira. Revista de Arqueología. Vol. 25 (1), pp. 10-46.

Ramallo, V.; Muzzio, M. J.; Motti, B. M.; Salceda, S. y Bailliet, G. 2009. "Linajes masculinos y su diversidad en comunidades wichi de Formosa". En: Revista del Museo de Antropología Vol. 2, pp. 67-74.

Ramallo, V.; Muzzio, M.; Santos, M. R.; Jurado Medina, L.S.; Bravi, C. M. y Bailliet, G. 2011. "Native male founder lineages of America". Current Research in the Pleistocene, pp. 29-32.

Ramallo, V.; Salceda, S. y Bailliet, G. 2007. "Microsatélites del cromosoma Y en comunidades aborígenes. Formoseñas”. En: XXVII Encuentro de Geohistoria Regional. Asunción- Paraguay.

Rivera Casanovas, C. 2003. "Identidades compartidas en el sur de Bolivia: Interacciones entre las Poblaciones Prehispánicas del Valle de Cinti y las Tierras Bajas del Sudeste". En: La Mitad Verde del Mundo Andino: Estado Actual de las Investigaciones Arqueológicas en la Vertiente Oriental de los Andes y Tierras 
Bajas de Bolivia y Argentina. Universidad Nacional de Jujuy, Argentina. Ortiz G. y Ventura B. (Eds.), pp. 179-203.

Ryden, S. 1948. Cord impression Decoration in Chaco Ceramics. Archivos Ethnos. V. 11-6. Buenos Aires.

Salceda, S. A. y Calandra, H. A. 2003. La planicie chaqueña: orígenes de su historia. Duodécimo Congreso Nacional y Regional de Historia Argentina. Academia Nacional de la Historia. Buenos Aires. pp. 1-18.

Schmitz, Pedro I.; Rogge, J. H.; Osorio Rosa, A. y Beber, M. V. 1998. “Aterros Indígenas no Pantanal do Matto Grosso do Sul”. En: Pesquisas Antropología. Vol. 54, pp. 1-271, Instituto Anchietano de Pesquisas, Río Grande do Sul.

Slatkin, M. 1995. "A measure of population subdivisión base don microsatellite allele frequencies. Genetics. Vol. 139, pp. 457-462.

Underhill, P. A.; Passarino, G.; Lin, A. A.; Shen, P.; Mirazon, L. M.; Foley, R. A.; Oefner, P. J. y Cavalli-Sforza, L.L. 2001. "The phylogeography of Y chromosome binary haplotypes and the origins of modern human populations". En: Annual of Human Genetics. Vol. 65, pp. 43-62.

Weir, B. S. 1996. "Genetic Data Analysis II: Methods for discrete population genetic data". En: Sunderland: Sinauer Assoc., Inc., Sunderland, MA, USA.

Weir, B. S. y Cockerham, C. C. 1984. "Estimating F-statistics for the analysis of population structure”. En: Evolution, Vol. 38, pp. 1358-1370. 